\title{
Preparation and Characterization of Functionalized Polypropylene with Acrylamide and Itaconic Acid
}

\author{
A. R. Oromiehie' ${ }^{1}$, H. Ebadi-Dehaghani ${ }^{2}$, K. Ansari ${ }^{1}$, K. Karimi ${ }^{2}$, Z. Rahmani' ${ }^{2}$, S. Mirbagheri1 \\ ${ }^{1}$ Iran Polymer and Petrochemical Institute, Tehran, Iran \\ ${ }^{2}$ Shahreza Branch, Islamic Azad University, Shahreza, Iran \\ Email: ${ }^{*}$ ebadi@iaush.ac.ir
}

Received September 2014

\begin{abstract}
Functionalized polypropylene with acryl amide (AAm) and itaconic acid (IA) were prepared in the molten state in the presence of dicumyl peroxide. The effects of the concentration of both monomers on the degree of functionalization and properties of the products were investigated by FT-IR, contact angle measurement and DSC analysis. It was found that the degree of functionalization depends on the initial concentration of both monomers that used in the reaction. The influence of the AAm and IA content on the melting and crystallization temperature of PP was investigated by DSC. The contact angle of water on film surfaces of the functionalized PP (PP-g-AAm and PP-g-IA) decreased with increasing modified polymer content. From FT-IR spectra of functionalized PP a calculation was made of carbonyl index on the films surfaces. It was found that the higher intensity of the carbonyl index, the lower contact angle value and the lower crystallinity confirmed the existence of functionalized AAm and/or IA in PP. It was concluded from the different characterization methods that the polarity and percentage of functionalized PP were increased up to $3 \mathrm{phr}$ for both monomers, and then it was decreased by increasing the amount of monomers and had a threshold value, due to nucleating agents of monomers in PP.
\end{abstract}

\section{Keywords}

Functionalized Polypropylene, Acryl Amide, Itaconic Acid, FT-IR, Contact Angle

\section{Introduction}

Funcionalization of polyolefin's (POs) through graft copolymerization containing polar and active functional groups onto polymer chain has been the subject of intense research during recent years [1]-[8]. By this method, some properties of polyolefins such as polarity, adhesion with metal, glass or ceramic, and compatibility with polyamides, polyesters, etc. could be greatly improved. Isotactic polypropylene (iPP) is one of the most impor-

*Corresponding author.

How to cite this paper: Oromiehie, A.R., Ebadi-Dehaghani, H., Ansari, K., Karimi, K., Rahmani, Z. and Mirbagheri, S. (2014) Preparation and Characterization of Functionalized Polypropylene with Acrylamide and Itaconic Acid. Journal of Materials Science and Chemical Engineering, 2, 43-51. http://dx.doi.org/10.4236/msce.2014.210007 
tant thermoplastics in the world today. PP has gained an important position among other POs due to its versatility and broad range of applications [9]. However, the application of PP in some technologically important fields seems to be limited due to its lack of polar functional groups as well as its inherent incompatibility with additives and other polar polymers [10] [11].

Chemical modification of PP by mean of grafting unsaturated polar groups onto the backbone of non-polar resins has proven to be available method of providing PP with additional properties [10]. In fact, these kinds of grafted polymers have been widely used to improve interfacial adhesion between the components in polymer blends [5] [6] [12]-[14]. A large number of reports have focused on the fictionalization of PP with maleic anhydride and other polar monomers such as unsaturated carboxylic derives and vinyl or acrylic substances containing more than one functional groups [10] [11] [14]-[26].

Since little research work has been published using acryl amide and itaconic acid as polar monomers, which are characterized by having double functionality, we have carried out a study that looking for the possibility of placing these monomers onto PP chains.

From the literature, it can be deduced that the functionalizing mechanism, concentration, structure and location of the functionalized groups are to a large extent influenced by the functionalizing method and the reaction conditions (temperature, pressure, concentration, solvent, additive, etc.). In this work the organic peroxide structure, the polypropylene grade, the melt temperature, and the reaction time were kept constant. Only concentration of the monomers was varied. Functionalization reactions of monomers on PP were prepared by melt mixing carried out in an internal mixer (Haake rheometer System 90). The effects of the concentration of both monomers (acryl amide and itaconic acid) on the degree of functionalization and the properties of functionalized PP (PP-g-AAm and PP-g-IA) were investigated by FT-IR spectroscopy, contact angle measurement and thermal analysis respectively.

This template, created in MS Word 2003 and saved as "Word 97-2003 \& 6.0/95-RTF" for the PC, provides authors with most of the formatting specifications needed for preparing electronic versions of their papers. All standard paper components have been specified for three reasons: 1) ease of use when formatting individual papers, 2) automatic compliance to electronic requirements that facilitate the concurrent or later production of electronic products, and 3) conformity of style throughout a journal paper. Margins, column widths, line spacing, and type styles are built-in; examples of the type styles are provided throughout this document and are identified in italic type, within parentheses, following the example. Some components, such as multi-leveled equations, graphics, and tables are not prescribed, although the various table text styles are provided. The formatter will need to create these components, incorporating the applicable criteria that follow.

\section{Experimental}

\subsection{Materials}

Isotactic Polypropylene (iPP) (V30S) was from Arak Petrochemical Co. Iran, acrylamide (AAm), itaconic acid (IA), dicumyl peroxide (DCP), acetone and xylene were from Merck Co. and Irganox B225 from Ciba Co. All of materials were used as received.

\subsection{Preparation of Functionalized Polypropylene}

Functionalization reactions on PP were carried out in an internal mixer (Rheomix 60) attached to a microprocessor (Haake Rheometer System 90). In both cases the process reaction was carried out in optimum processing condition [14] [21] at 1700C and $60 \mathrm{rpm}$ for $8 \mathrm{~min}$, PP was mixed with anti-oxidant and introduced into the mixer. After $2 \mathrm{~min}$., $0.1 \mathrm{phr}$ of DCP was added and after $1 \mathrm{~min}$ monomer was added to the molten polymer. Five minutes later the reactor was opened and the melt mixture cooled and pressed into sheets to facilitate cutting into small pellets. The initial monomer concentration was varied from 1 - 4 phr.

\subsection{Preparation of Samples}

In order to remove the unreacted monomers, the functionalized PP ( 5 gr) was dissolved in boiling xylene under reflux until a clear solution was obtained (about $30 \mathrm{~min}$ ). The warm solution was precipitated in acetone (50 ml) and filtered to obtain purified polymer, which was dried in a vacuum oven for $24 \mathrm{hr}$. at $110^{\circ} \mathrm{C}$. 


\subsection{Characterization}

\subsubsection{FT-IR Spectroscopy}

The evidence of functionalizing as well as its extent was determined by FT-IR spectroscopy. Thin films of PP and functionalized PP were obtained by compression molding between steel plates covered with thin aluminum sheets at 1800 C. IR spectra were recorded on a Bruker Equinox 55 spectrometer from $400-4000 \mathrm{~cm}^{-1}$.

\subsubsection{Contact Angle Measurement}

The contact angles of distilled water on the films of $100 \mu \mathrm{m}$ thick were measured by the sessile drop method performed at room temperature by using a contact angle device Kruss Model G10 GmbH, equipped with software for drop-shape analysis. The liquid drop $(\sim 2-3 \mu \mathrm{l})$ was placed onto the sample surface with a micro syringe. The drop image was recorded by a digitalized video camera. The drop shape was solved numerically and fitted by means of mathematical functions. Each contact angle is the average value of 6 measurements. The contact angle was obtained according to the following equation [19]:

$$
\theta=2 \tan -1(2 h / w)
$$

where, $\theta$ is the contact angle, $h$ is the height and $w$ is the wide of the droplet that were measured from the photograph and from the geometric considerations.

\subsubsection{Thermal analysis (DSC)}

Thermal properties of functionalized PP were recorded on a differential scanning calorimeter (DSC), Perkin-Elmer Model Pyris1.The analysis were carried out at constant heating rate of $100 \mathrm{C} / \mathrm{min}$ in the temperature range of $250 \mathrm{C}$ to $2000 \mathrm{C}$ under nitrogen atmosphere. The sample was kept at $2000 \mathrm{C}$ for $5 \mathrm{~min}$. and then cold to room temperature at a rate of $100 \mathrm{C} / \mathrm{min}$.

The values obtained for the heat of fusion, from DSC measurement, for PP and functionalized PP samples were used to estimate the percentage of crystallinity $\left(\mathrm{X}_{\mathrm{c}}\right)$. This was done by using the value of fusion enthalpy $\Delta \mathrm{H}_{\mathrm{f}}$ of $100 \%$ crystalline PP as $50 \mathrm{cal} / \mathrm{g}$ [20]. The crystallinity of various samples was obtained according to the following equation:

$$
\text { \%Crystallinity }\left(X_{c}\right)=\left(\Delta H_{f} / \Delta H_{f} *\right) \times 100
$$

where $\Delta H f$ is the heat of fusion of functionalised PP and $\Delta H_{f}^{*}$ is the heat of fusion of $100 \%$ crystalline PP.

\section{Results and Discussion}

\subsection{FT-IR Spectroscopy}

FT-IR Spectroscopy is a well-accepted method for identification and quantification of the polar groups that present in a polymer surface. The IR spectrum of functionalised PP (PP-g-AAm and PP-g-IA) with overall content of 0, 1, 2, 3 and 4 phr of monomers are given in Figure 1 and Figure 2 respectively. The FT-IR spectra of the plain PP-g-AAm are shown in Figure 1. It can clearly be seen that the absorption peak at $1665 \mathrm{~cm}^{-1}$ may be assigned to the $\mathrm{C}=\mathrm{O}$ stretching vibration of the amide group. This peak may be attributed to the carbonyl stretching vibration of amide group and indication of the presence of grafted acrylamide on PP [26]. It also can be seen that the intensity of carbonyl peaks increased by increasing the AAm monomer content from 1 up to 3 phr. This result could be attributed to AAm moieties grafted onto PP chains. But the intensity of the carbonyl peaks decreased by more adding of AAm ( $>3 \mathrm{phr})$. This is due to the AAm homopolymerization [16] [26].

The FT-IR spectra of PP-g-IA, with different amounts of monomer incorporated in the polypropylene chains are shown in Figure 2. It is possible to distinguish the carbonyl absorption peak at $1710 \mathrm{~cm}^{-1}$ that due to the presence of polar carboxylic acid of itaconic acid and the second absorption peak in the carbonyl region that appears at 1780 $\mathrm{cm}^{-1}$ is related to the carbonyl group of itaconic anhydride that probably formed during the functionalization reaction. It can be seen in Figure 2 that the intensity of the carbonyl peaks increased by increasing the IA monomer content led to an increase in the functionality. For this particular study, it is seen that the ratio of functionalizing depends on the initial monomer concentration for low values and particularly does not show any significant increase for higher monomer content. This could be due to the homopolymerization tendency of itaconic acid [16] [23]. 


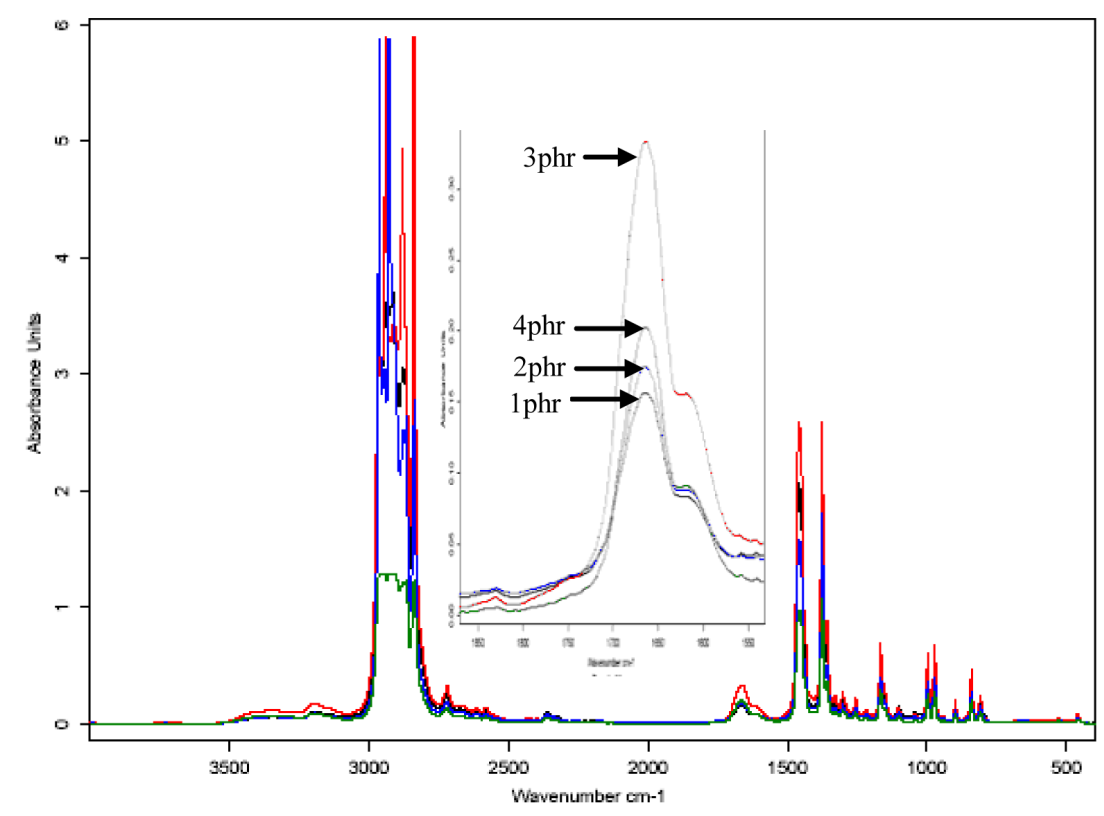

Figure 1. FT-IR spectra of PP-g-AAm.

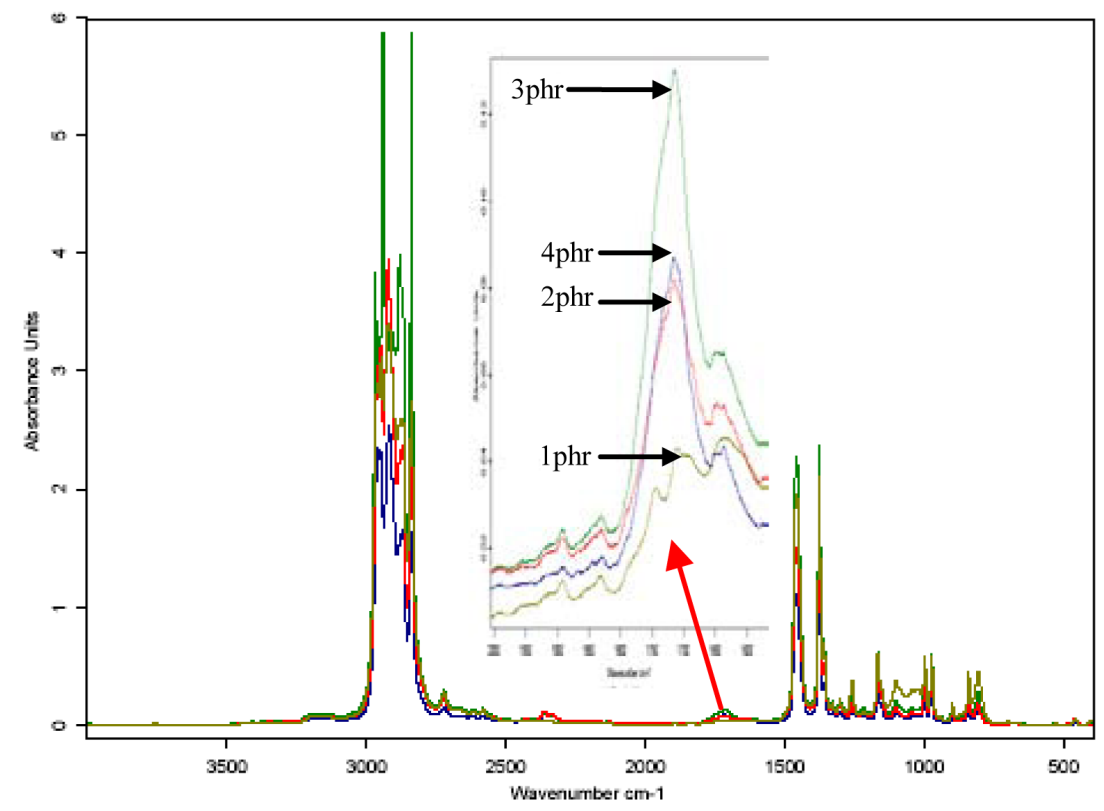

Figure 2. FT-IR spectra of PP-g-IA.

From FT-IR spectra the Carbonyl Index (CI) was calculated as a ratio of the intensity of polar carbonyl group from the functionalized PP and methyl group from PP ( $A_{F P P}$ and $A_{P P}$ respectively). Since CI is a relative measurement, a calibration curve must be constructed, and the CI was calculated as: [17]

$$
C I=A_{F P P} / A_{P P}
$$

The ratio between the intensity of the peak at $1665 \mathrm{~cm}^{-1}$ due to the presence of the polar carbonyl group from acrylamide and methyl group from PP at $1167 \mathrm{~cm}^{-1}$, which can be considered as a measure of the extent of functionalising, is shown in Figure 3 and calculated as:

$$
C I=A_{1665} / A_{1167}
$$




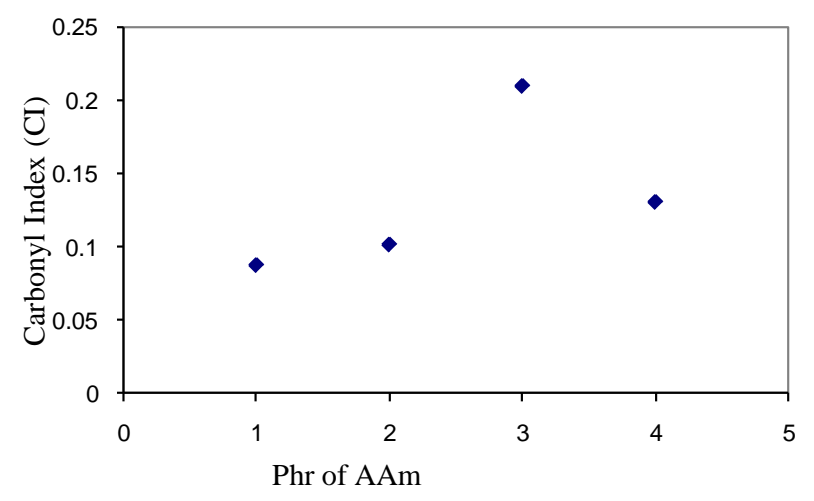

Figure 3. Carbonyl Index of PP-g-AAm.

The carbonyl index (CI) as the ratio between the intensity of the absorption peak of carboxylic group of itaconic acid and $\mathrm{CH}_{3}$ group of PP, was shown in Figure 4, which can be considered as a measure of the extent of functionalizing that calculated by using the following equation:

$$
C I=A_{1710} / A_{1167}
$$

It can be inferred from this increase on $\mathrm{C}=\mathrm{O}$ stretching absorbance that the films' surfaces contain increased amounts of $\mathrm{C}=\mathrm{O}$ polar groups as the content of functionalized polymer is also increased.

\subsection{Contact Angle Measurement}

Contact angle measurement of a solid/liquid interface is widely used method for the determination of surface energy of solid polymers. This technique is an excellent method for characterizing the surface that gives information on the wetting behavior of a liquid on a solid surface and determines the polarity of the functionalized polymer [19] [24] [27]. The polarity of the functionalized PP was measured by contact angle of distilled water on the sample films. The contact angle for a pure PP film without any functionalized monomer was measured and it was $97^{\circ}$. The contact angle of the functionalized PP samples were measured and noted that it decreases as the monomer content increases. The contact angle of water on the PP-g-AAm and PP-g-IA copolymers is indicated in Figure 5 and Figure 6.

The contact angle values of functionalized PP (PP-g-AAm) decreased by increasing in the content of AAm monomers up to $3 \mathrm{phr}$, when compared with the values of the control PP, but it increased by more content of monomer Figure 5. This may be due to AAM homopolymerization [24] [25]. The contact angle is very sensitive to the chemical and structural changes occurring on the polymer surface. In order to obtain the polar and dispersion components of the surface free energy the following equation was used [19] [24]

$$
W A=\gamma(1+\operatorname{Cos} \theta)
$$

That (WA) is the work of adhesion, $(\theta)$ is contact angle at equilibrium and $(\gamma)$ is free energy for distill water and is $72.2 \mathrm{mN} / \mathrm{m}$. The results of work of adhesion calculated according to above equation. In the case of PP-g-IA the contact angle decrease as the itaconic acid contents were increased. The results of contact angles and the determining polarity rate of samples are shown in Figure 6.

Functionalization of polymer with polar functional groups (monomers) is the cause of increasing in hydrophilic properties of total product. Increasing the hydrophilic properties is caused to higher adhesion of functional polymer [15]. These phenomena can be seen in the results of contact angle of water on the surface of samples films [15] [16].

\subsection{Thermal Analysis}

The DSC curves and thermal behavior of PP and functionalized PP (PP-g-AAm) are given in Figure 7 and Table 1. It was found that the functionalizing process did not affect the melting temperature of functionalized PP samples. The values obtained for heat of fusion, from DSC measurements, for PP and functionalized PP samples were used to estimate the percentage of crystallinity (Xc). This was done by using the value for enthalpy of fusion of 


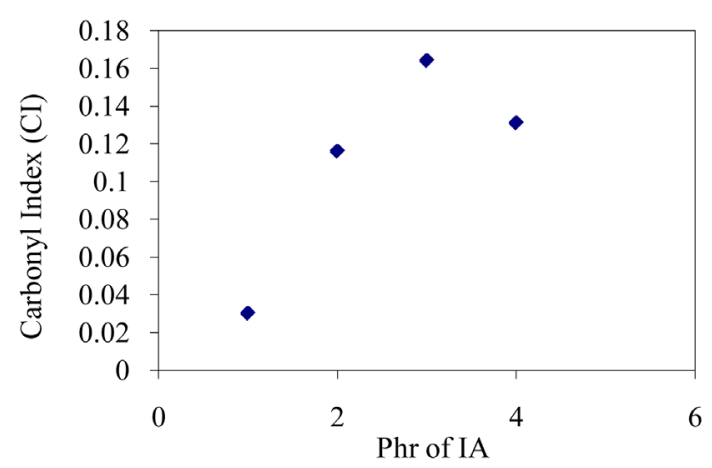

Figure 4. Carbonyl Index of PP-g-IA.

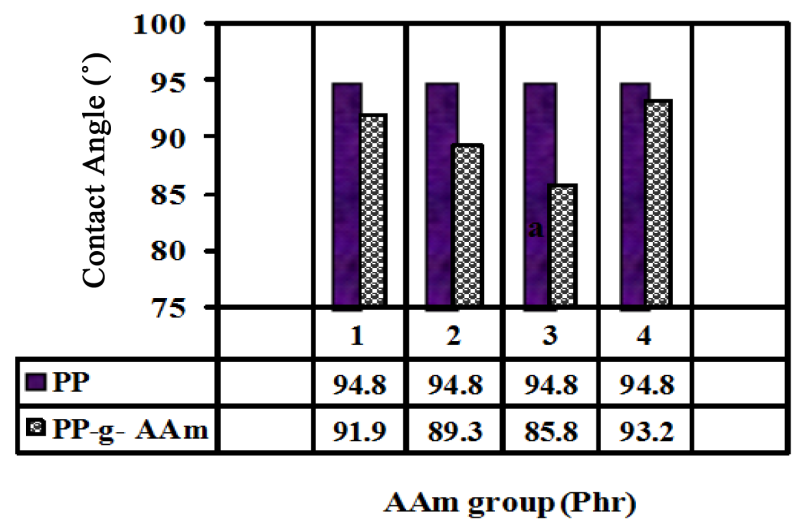

Figure 5. Contact angle results of PP-g-AAm.

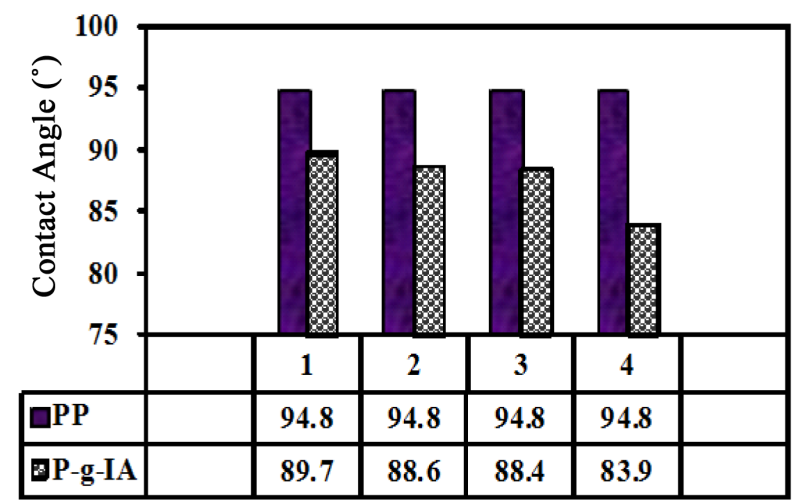

IA group (Phr)

Figure 6. Contact angle results of PP-g-IA.

Table 1. Thermal analysis of PP-g-AAm.

\begin{tabular}{ccccc}
\hline Monomer (phr) & $\mathbf{T}_{\mathbf{m}}\left({ }^{\circ} \mathbf{C}\right)$ & $\Delta \boldsymbol{H}_{f}(\mathbf{m c a l} / \mathbf{m g})$ & $\mathbf{T c}\left({ }^{\circ} \mathbf{C}\right)$ & $\mathbf{T m}\left({ }^{\circ} \mathbf{C}\right)$ \\
\hline 0 & 168.97 & 22.57 & 121.99 & 45.14 \\
1 & 166.75 & 16.52 & 124 & 33 \\
2 & 165.85 & 17.48 & 125.56 & 34.96 \\
$\mathbf{3}$ & $\mathbf{1 6 5 . 8 9}$ & $\mathbf{1 6 . 4 2}$ & $\mathbf{1 2 5 . 1 8}$ & $\mathbf{3 2 . 8 4}$ \\
4 & 164.55 & 16.66 & 123.3 & 33.32 \\
\hline
\end{tabular}




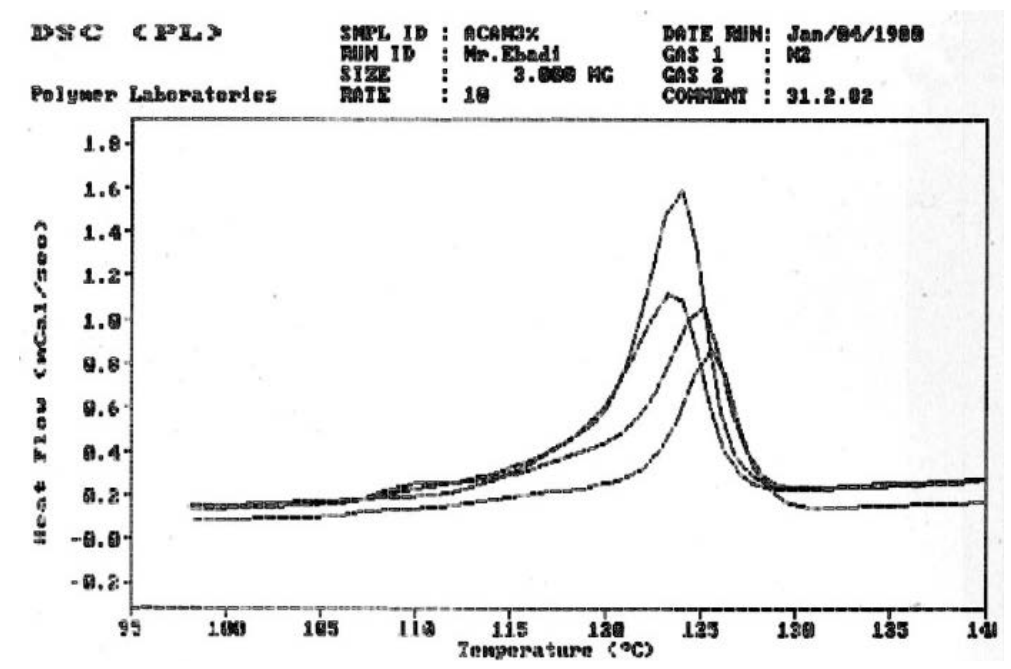

Figure 7. DSC crystalline temperature of PP-g-AAm.

$100 \%$ crystalline pp that is $50 \mathrm{cal} / \mathrm{g}$. The heat of fusion is directly proportional to the amount of crystalline PP in sample. It decreases linearly with an increase in functionalizing percentage, Table 1. An apparent decrease in heat of fusion was due to the decrease in weight fraction of crystalline PP in copolymer due to an incorporation of AAm. A similar trend was observed by Sath.et al. [28] it was observed that the crystallization temperature $\left(\mathrm{T}_{\mathrm{c}}\right)$ of functionalized samples was higher than for PP. The observed increase in crystallization temperature can be attributed to the AAm acting as nucleating agent, and also because of the connection of the carbonyl group to PP [26]-[28]. It can be shown in Table 1 that by increasing the percent of monomer to 3 phr. the percentage of crystallinity is decreased, but it slightly increased by more addition of acrylamide monomers. It may be due to AAm homopolymerization [24].

The DSC curves and thermal behavior of PP-g-IA are given in Figure 8 and Table 2. It was found that the functionalizing process did not affect the melting temperature of PP-g-IA samples as it was with PP-g-AAm samples. But it was noted that the percentage of crystallinity reduced by adding 1 phr portion of IA monomer but it slightly increases by increasing the percentage of IA monomer. As the heat of fusion is directly proportional to the amount of crystalline PP in the sample, it decreases linearly with an increase in grafting percentage. An apparent decrease in heat of fusion was due to the decrease in weight fraction of crystalline PP in copolymer due to an incorporation of IA that it might be due to IA homopolymerization [24]. In comparison the functionality, polarity and crystal linty behavior of PP-g-AAm and PP-g-IA, it was observed that there were some differences between these copolymers especially when the portions of monomers were increased.

\section{Conclusion}

Polypropylene was functionalized with different ratios of acrylamide and itaconic acid in the presence of DCP in optimum processing conditions by melts mixing. The effect of the modified polymer content and the properties of functionalized PP were characterized by FT-IR spectroscopy, contact angle measurement and DSC. It was concluded that the degree of functionalized PP depends on the concentration of both monomers (AAm and IA). It was found that the monomer content from 1 to $3 \mathrm{phr}$ had satisfied results, but in higher amount of monomers the functionality was decreased. This is due to homopolymerization of monomers during processing and owing to the nucleating effect of monomers in PP as well. FT-IR results confirmed that the AAm or IA was grafted onto molecular chains of PP. The intensity of the carbonyl and carboxyl polar groups confirmed the enhancement of functionality. The contact angle of distill water on the surface films of functionalized PP decreases when the modified polymer content increases. This is due to increasing in degree of polarity of copolymers, also confirmed the improvement of functionality. The functionalization of AAm and IA onto PP do not change melting temperature and increase the crystallization temperature of polymer in both PP-g-AAm and PP-g-IA copolymers. Moreover, increasing in crystalline temperature could be attributed to monomer molecule acting as nucleating agent in PP and also because of the connection of the carbonyl group to PP. But the decreasing in the crystalline percentage may be due to homopolymerization of the AAm and IA monomers. 


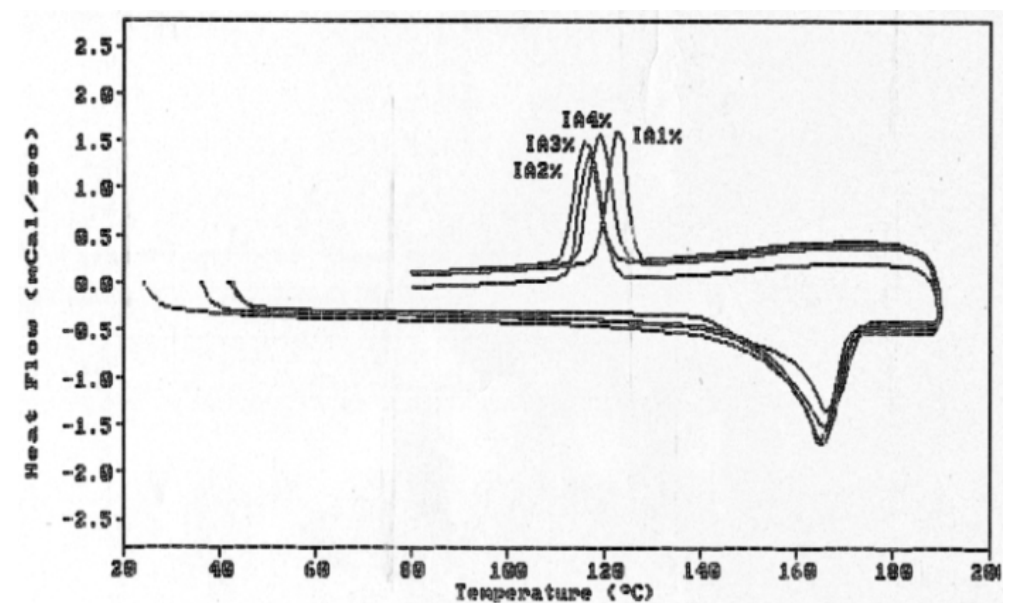

Figure 8. DSC thermogram of PP-g-IA.

Table 2. Thermal analysis of PP-g-IA.

\begin{tabular}{ccccc}
\hline Monomer $(\mathbf{p h r})$ & $\mathbf{T}_{\mathbf{m}}\left({ }^{\circ} \mathbf{C}\right)$ & $\Delta \boldsymbol{H}_{f}(\mathbf{m c a l} / \mathbf{m g})$ & $\mathbf{T c}\left({ }^{\circ} \mathbf{C}\right)$ & $\mathbf{T m}\left({ }^{\circ} \mathbf{C}\right)$ \\
\hline 0 & 168.97 & 22.57 & 121.99 & 45.14 \\
1 & 165.96 & 19.37 & 123.14 & 38.74 \\
2 & 166 & 20 & 117 & 40 \\
$\mathbf{3}$ & $\mathbf{1 6 4 . 8 9}$ & $\mathbf{1 7}$ & $\mathbf{1 1 6}$ & $\mathbf{3 4}$ \\
4 & 166.46 & 18.46 & 119.2 & 36.92 \\
\hline
\end{tabular}

\section{Acknowledgement}

Thanks to the members of Iran Polymer and Petrochemical Institute for their help and assistance.

\section{References}

[1] Jois, Y. and Harrison, H.J.B. (1996) J Macromol Sci-Rev Macromol Chem.Phy, C36, 433-453.

[2] Abhimany, O. (2000) Poly. Pre Print, 41, 1546-1547.

[3] Li, Y., Xie, X.-M. and Cuo, B.-H. (2001) Study on Styrene-Assisted Melt Free-Radical Grafting of Maleic Anhydride onto Polypropylene. Polymer, 42, 3410-.3425.

[4] George, J., Ta-Yong., W. and Chung-Hsien, H. (1996) Polym. PrePrint, 37, 352-353.

[5] Wang, Q., Liu C.S. and Chen, Z. (2001) Pan-Milling Preparation of Polypropylene-graft-Maleic Anhydride and Its Compatibilizing Effect on Polyamide 6/Polypropylene Blend. Polymer Journal, 33, 522-527. http://dx.doi.org/10.1295/polymj.33.522

[6] Huang, H. and Liu, N.C. (1998) Nondegradative melt Functionalization of Polypropylene with Glycidyl Methacrylate. Journal of Applied Polymer Science, 67, 1957-1963. http://dx.doi.org/10.1002/(SICI)1097-4628(19980321)67:12<1957::AID-APP1>3.0.CO;2-M

[7] Chandranap, P. and Bhattacharya, S.N. (2000) Reactive Processing of Polyolefins with MAH and GMA in the Presence of Various Additives. Journal of Applied Polymer Science, 78, 2405-2415. http://dx.doi.org/10.1002/1097-4628(20001220)78:13<2405::AID-APP180>3.0.CO;2-Y

[8] Garcia-Martinez, J.M., Cofrades, A.G., Languna, O., Areso, S. and Collar, E.P. (2000) Influence of Reactant Concentration and Reaction Time in the Chemical Modification Process of Polypropylene by p-Phenylen-bis-Maleamic Acid in the Melt. European Polymer Journal, 36, 2253-2263. http://dx.doi.org/10.1016/S0014-3057(99)00277-3

[9] Mehta, K., Kumar, S., Chauhan, G.S. and Mishra, B.N. (1990) Grafting onto Isotactic polypropYlene. III. Gamma Rays Induced Graft Copolymerization of Water Soluble Vinyl Monomers. Journal of Applied Polymer Science, 41, 1171-1180. http://dx.doi.org/10.1002/app.1990.070410526

[10] Xu, G. and Lin, S. (1994) J. Macromol Sci-Rev Macromol Chem. Phy., C34, 555-606. 
[11] Naqvi, M.K. and Choudhary, M.S. (1996) J. Macromol Sci-Rev Macromol Chem. Phy., C36, 601-625.

[12] Paul, D.R. and Newman, S. (1978) Academic Press, N.Y.

[13] Garcia-Martinez, J., Laguna, M.O. and Collar, E.P. (1998) Chemical Modification of Polypropylenes by Maleic Anhydride: Influence of Stereospecificity and Process Conditions. Journal of Applied Polymer Science, 68, 483-495. http://dx.doi.org/10.1002/(SICI)1097-4628(19980418)68:3<483::AID-APP14>3.0.CO;2-W

[14] Oromiehie, A.R., Hashemi, S.A., Waters, D.N. and Meldrum, I.G. (1997) Functionalisation of Polypropylene with Maleic Anhydride and Acrylic Acid for Compatibilising Blends of Polypropylene with Poly(ethylene terephthalate). Polymer International, 42, 117-120. http://dx.doi.org/10.1002/(SICI)1097-0126(199701)42:1<117::AID-PI690>3.0.CO;2-N

[15] Gaylord, N.G. (1985) US Patent No. 456056.

[16] Yazdani-Pedram, M., Vega, H. and Quijada, R. (1996) Functionalization of Polypropylene by grafting with Itaconic Acid. Macromol Rapid Comm., 17, 577-582.

[17] Nachtigall, S.M.B., Stedile, F.C., Felix, A.H.O. and Mauler, R.S. (1999) Polypropylene Functionalization with Vinyltriethoxysilane. Journal of Applied Polymer Science, 72, 1313-1319. http://dx.doi.org/10.1002/(SICI)1097-4628(19990606)72:10<1313::AID-APP11>3.0.CO;2-D

[18] Wong, B. and Baker, W. (1997) Melt Rheology of Graft Modified Polypropylene. Polymer, 38, 2781-2789. http://dx.doi.org/10.1016/S0032-3861(97)85615-7

[19] Wu, S. (1982) Polymer Interface and Adhesion. Marcel Dekker, New York.

[20] Martuscelli, E., Silvestre, C. and Abate, G. (1982) Morphology, Crystallization and Melting Behavior of Films of Isotactic Polypropylene Blended with Ethylene-Propylene Copolymers and Polyisobutylene. Polymer, 23, $229-237$. http://dx.doi.org/10.1016/0032-3861(82)90306-8

[21] Oromiehie, A.R., Ebadi, H., Mirbagheri, S. and Shahrivari, Z. (2003) Proceedings of the APME-5, Conference, Montreal, Canada, June 21-26, p. 86.

[22] Bettini, S.H.P. and Agnelli, J.A.M. (1999) Grafting of Maleic Anhydride onto Polypropylene by Reactive Processing. I. Effect of Maleic Anhydride and Peroxide Concentrations on the Reaction. Journal of Applied Polymer Science, 74, 247-255. http://dx.doi.org/10.1002/(SICI)1097-4628(19991010)74:2<247::AID-APP2>3.0.CO;2-A

[23] Yazdani-Pedram, M., Vega, H. and Quijada, R. (2001) 42, 4751-4758.

[24] Sanchez-Valdes, S., Guerrero-Salazar, C., RamosdeValle, L.F., Lopez-Quintanilla, M., Yasfiez-Flores, I., Orona- Villarreal, F. and Ramirez-Vergas, R. (1997) J. Polym. Eng., 17, 257-267.

[25] Kubota, H. (1993) Photografting of Acrylonitrile and Methacrylic acid on Polyethylene Film under Air Atmosphere. Journal of Applied Polymer Science, 48, 1717-1721. http://dx.doi.org/10.1002/app.1993.070481004

[26] Zhihui, Y., Xiaomin, Z. and Yiajie, Z. (1996) Synthesis and Characterization of Polypropylene Grafted by Acrylamide. Polymer-Plastics Technology and Engineering, 35, 905-915. http://dx.doi.org/10.1080/03602559608000606

[27] Sathe, S.N., Srinivasarao, G.S. and Devi, S. (1994) Grafting of Maleic Anhydride onto Polypropylene: Synthesis and Characterization. Journal of Applied Polymer Science, 53, 239-245.

[28] Vitt, E. and Shull, K.R. (1995) Equilibrium Contact Angle for Polymer/Polymer Interfaces. Macromolecules, 28, 63496353. http://dx.doi.org/10.1021/ma00122a049 